Version définitive du manuscrit publiée dans / Final version of the manuscript published in :

Trends in Analytical Chemistry (2015), Vol. 71, p. 157-168, DOI: 10.1016/j.trac.2015.02.021

Journal homepage : http://www.elsevier.com/locate/trac

\title{
Solvent-free extraction of food and natural products
}

\author{
Farid Chemat ${ }^{\mathrm{a}, *}$, Anne Sylvie Fabiano-Tixier ${ }^{\mathrm{a}}$, Maryline Abert Vian ${ }^{\mathrm{a}}$, Tamara Allaf ${ }^{\mathrm{b}}$, \\ Eugene Vorobiev ${ }^{c}$ \\ a Avignon University, INRA, UMR 408, GREEN Extraction Team, F-84000 Avignon, France \\ b ABCAR-DIC, F-17100 La Rochelle, France \\ ${ }^{\mathrm{c}}$ Laboratoire Transformations Intégrées de la Matière Renouvelable, Équipe Technologies Agro-Industrielles, Université de Technologie de Compiègne (UTC), \\ F-60205 Compiègne, France
}

Keywords:

Degradation

Extraction

Extrusion

Food

Microwave

Natural product

Plant cell

Pressing

Pulsed electric field

Solvent-free extraction

\section{A B S T R A C T}

This review presents useful and green techniques of solvent-free extraction used in ancient times, such as extraction of olive oil and citrus essential oil, and innovative techniques, such as pulsed electric field, microwave, instantaneous controlled pressure drop, and extrusion. We discuss the devices, their applications, mechanisms, and parameters influencing sample preparation prior to analysis of natural products.

\section{Contents}

1. Introduction

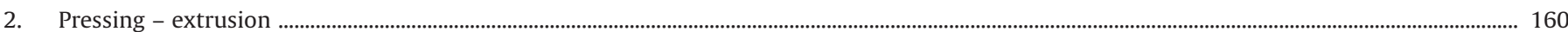

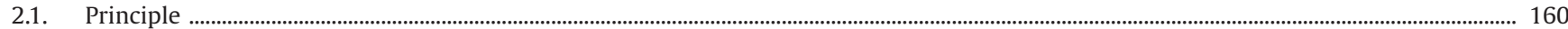

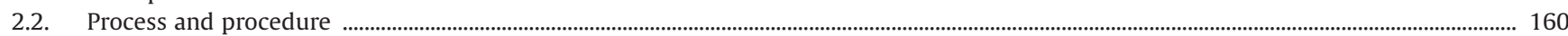

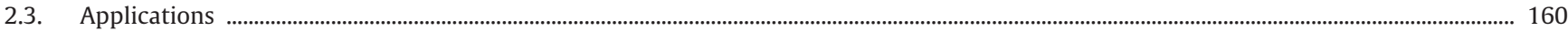

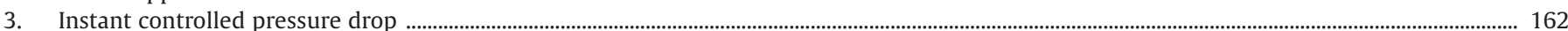

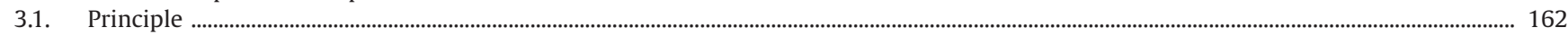

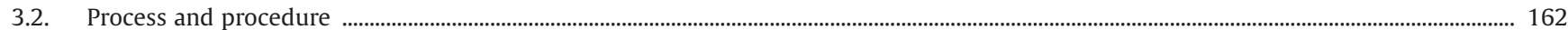

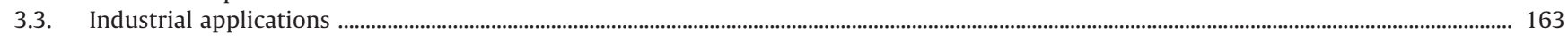

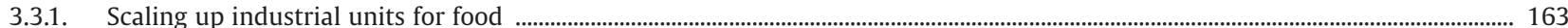

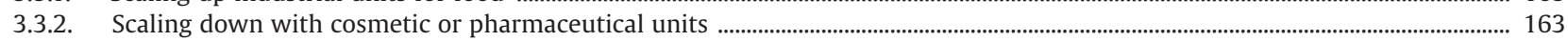

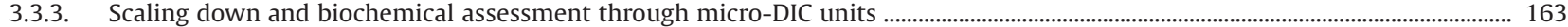

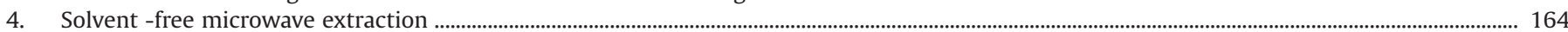

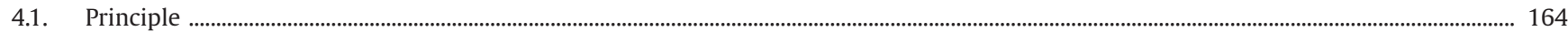

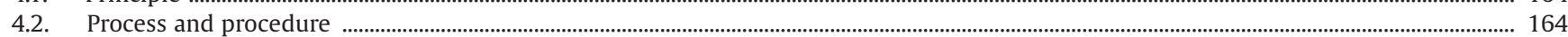

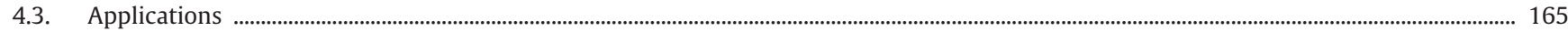

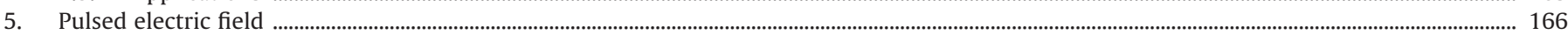

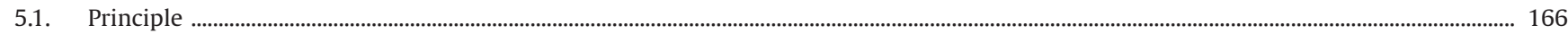

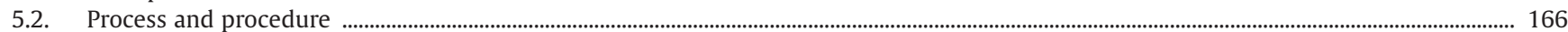

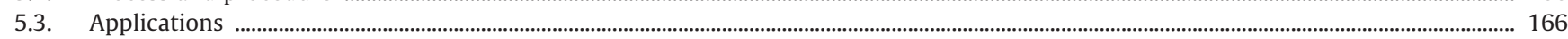

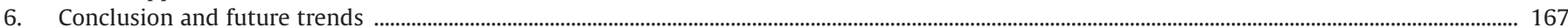

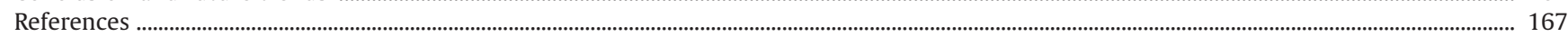

\footnotetext{
* Corresponding author. Tel.: +33490144465/+334901444 40; Fax: +33490144441.

E-mail address: Farid.Chemat@univ-avignon.fr (F. Chemat).
} 
Version définitive du manuscrit publiée dans / Final version of the manuscript published in :

Trends in Analytical Chemistry (2015), Vol. 71, p. 157-168, DOI: 10.1016/j.trac.2015.02.021

Journal homepage : http://www.elsevier.com/locate/trac

\section{Introduction}

An analytical procedure for natural products comprises three steps:

- extraction [e.g., solvent extraction in single step or many steps, Soxhlet extraction, Kumagawa extraction, Clevenger extraction, Likens-Nickerson simultaneous distillation-extraction, and solvent extraction intensified by innovative techniques, such as microwave (MW) or ultrasound, pressure liquid solvent extraction, and supercritical solvent extraction];

- evaporation of the solvent by distillation for concentration or purification; and,

- analysis [e.g., gas chromatography (GC), GC coupled with mass spectrometry (MS), high-performance liquid chromatography (HPLC) coupled to UV or MS, nuclear magnetic resonance (NMR), $\mathrm{X}$-ray diffraction (XRD) or gravimetry].

While the analysis step is complete after only seconds or minutes, extraction and distillation take at least several hours, even days, and are frequently carried out by prolonged heating and stirring in boiling solvent followed by prolonged heating to eliminate the solvent. Thus, the principal limiting step of chemical analysis is the extraction of the metabolites from the matrix into a solvent and then concentration by evaporation or transfer of the desired compounds by liquid-liquid extraction (LLE).

The conventional solvent-extraction procedure represents not only $80 \%$ of the total processing time, but also $90 \%$ of the required energy, and more than $99 \%$ of the solvent used for the whole analysis procedure. With decreasing fossil resources, such as petrol as a source of solvents, increasing energy prices and the drive to reduce $\mathrm{CO}_{2}$ emissions, researchers are being challenged to find new technologies in order to reduce or to eliminate solvent and energy consumption, to meet legal requirements on emissions, process safety and control, and to reduce cost and to increase quality and functionality. In the past 10 years, trends in analytical chemistry have turned toward the Green Analytical Chemistry (GAC) [1], which endeavors to develop new techniques that reduce the influence of chemicals on the environment. The challenge of the GAC is to develop techniques that meet the need for information while reducing the environmental impact of the analyses. For this reason, petroleumbased solvents have to be avoided (Fig. 1).

Solvent-free extraction of natural products has probably been used since the discovery of fire. Egyptians and Phoenicians, Jews and Arabs, Indians and Chinese, Greeks and Romans, and even Mayas and Aztecs all possessed innovative extraction processes used even for perfume, medicine or food. The first extraction techniques were discovered without using solvents. The most widely known extraction technique is extraction of olive oil using mechanical pressing, which was recognized as a solvent-free technique for millennia.

Virgin olive oils are extracted from olive fruits using only physical methods, which include crushing olives, malaxation of the resulting pastes and separation of the oily phase. Because of its location in mesocarp of cells and the use of purely mechanical apparatus for its extraction, virgin olive oil does not require further treatment before consumption. It therefore preserves a great number of volatile and non-volatile compounds, responsible for the aroma and the presence of antioxidant compounds that inhibit lipid autoxidation (i.e., there is no enzymatic oxidation by oxygen).

Another technique most common for aromas and perfumes is extraction of essential oils using cold pressing without heating and without any solvent. The principle of this mechanical process is based on machine squeezing the citrus pericarps at room temperature for the release of essential oil from citrus fruits, which are washed in cold running water. The essence is then isolated by decantation or centrifugation. The oleaginous cavities on the peel are pressed to

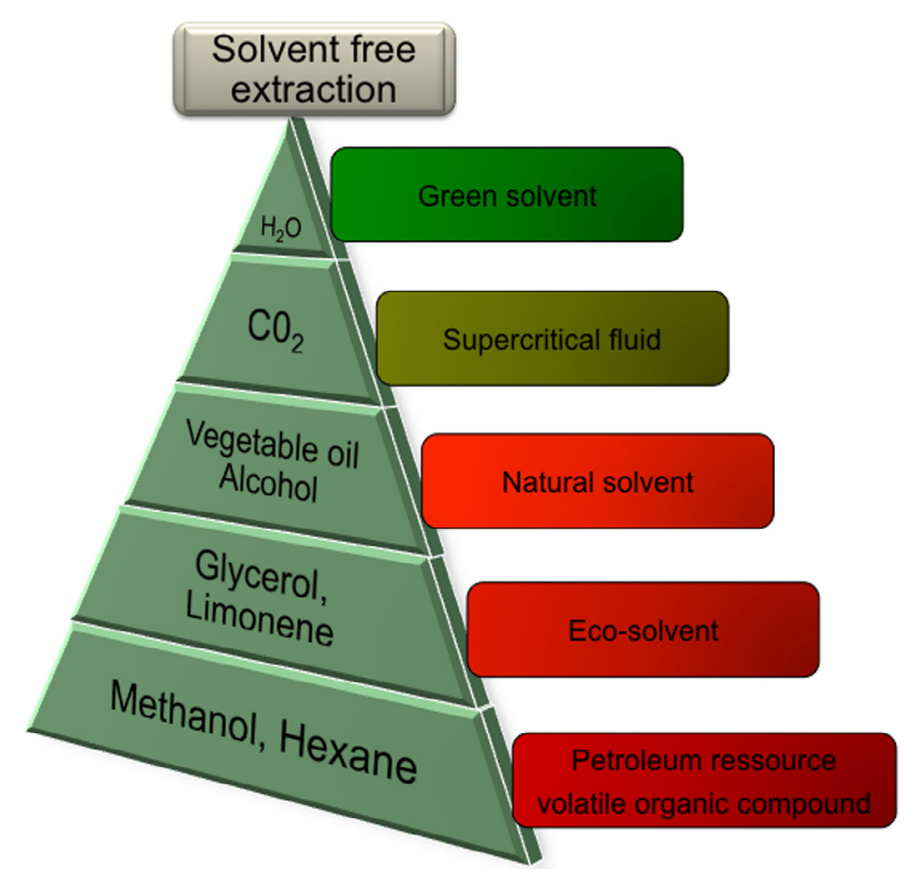

Fig. 1. From alternative solvents to solvent free.

burst by two horizontal ribbed rollers (sfumatrice) or a slowmoving Archimedean screw coupled to an abrasive shell (pelatrice) (Fig. 2), so the essential oil is released. The oil-water emulsion is separated after rinsing with a fine spray of water.

A central objective in extraction of natural products has been to develop green extraction techniques and more economically competitive processes for the efficient extraction of natural substances with potential application in the food, cosmetic or agrochemical industries [2]. Three major solutions have been identified to design and to demonstrate green extraction on laboratory and industrial scales to approach optimal consumption of raw materials, solvents and energy:

(1) improvement and optimization of existing processes;

(2) use of non-dedicated equipment; and,

(3) innovation in processes and procedures that eliminate solvents.

Industry and scientists should view the six principles of green extraction of natural products as a direction to establish an innovative, green label, charter and standard, and to innovate in not only process but also all aspects of chemistry: analysis, synthesis, purification, and extraction (Fig. 3).

In this context, the development of solvent-free techniques is of great interest in order to modernize conventional processes, making them greener, cleaner, safer and easier to perform. Several techniques, such as MW, instantaneous controlled pressure drop [Détente Instantanée Controlée (DIC)], pulsed electric field (PEF), and extrusion have been designed and successfully applied for solventfree extraction of secondary and primary metabolites.

These innovative techniques make it convenient to perform extraction very efficiently in the absence of any organic solvents, socalled dry-media conditions. The advantages of using dry-media conditions range from faster extraction with different selectivity to more economical conditions due to the absence of organic solvents. However, in spite of the possible advantages, there are few applications of solvent-free extraction. The slow evolution can to 
Version définitive du manuscrit publiée dans / Final version of the manuscript published in :

Trends in Analytical Chemistry (2015), Vol. 71, p. 157-168, DOI: 10.1016/j.trac.2015.02.021

\section{Journal homepage : http://www.elsevier.com/locate/trac}

some extent be explained by the required combination of reactor design of the technique (heat transfer, distribution of electric field and temperature) and complexity of plant matrices and target metabolites (chemical classes, and state of plant material).

Using MWs, PEF, extrusion, or DIC, solvent-free extraction can now be completed in minutes instead of hours with high reproducibility, eliminating the consumption of petroleum solvent and at the same time removing a time-consuming step in analytical chemistry: distillation, simplifying manipulation and work-up, increasing purity of the final product, eliminating post-treatment of wastewater and consuming only a fraction of the energy normally needed for a conventional solvent-extraction method. Using solventfree extraction, several classes of compounds, such as essential oils, aromas, edible oils, anti-oxidants, and other organic compounds, have been extracted efficiently from a variety of matrices (mainly animal tissues, food, and plant materials).

This review presents solvent-free extraction of food and natural products. It provides the necessary theoretical background and some details about techniques [MW, PEF, extrusion, or DIC], some applications and environmental impacts.

\section{Pressing - extrusion}

\subsection{Principle}

For the production of sugar, wine and fruit juices, or the dehydration of biological wastes, and in vegetable-oil industries, extraction is realized by pressing. The pressing phase is composed of a compression step to exude a fluid containing the target metabolites from the porous matrix. The cells of fruit and vegetable tissues are surrounded with membranes and closed by a cell wall embedded into a middle lamella. The components of the rigid wall prevent easy damage to the membranes, so they limit the efficiency of extraction by pressing. Two types of press are mainly used: hydraulic and screw. Using hydraulic pressing, the separation of the extract from the matrix is due to the application of a uniaxial force on the material. The pressure applied on the raw material can be very high (above $50 \mathrm{MPa}$ up to $100 \mathrm{MPa}$ for cocoa and up to $40 \mathrm{MPa}$ for olive oil) [3].

Screw presses have progressively replaced hydraulic presses. During pressing, a helical screw, in a barrel toward a restriction, conveys the raw material from the inlet to the outlet of the press. At the stage of the restriction area, shear forces are developed along the screw, and allow expression of oil contained in the seeds.

\subsection{Process and procedure}

Savoire et al. conducted a large review of influential factors in hydraulic and screw pressing [4]. The use of a piston is necessary to perform expression during hydraulic pressing, which puts a specific pressure on the material. A wide variety of screw presses exist and could be classified in three main categories:

- Expellers are composed of an horizontal screw rotating in a perforated barrel formed by regularly spaced metal bars to allow flow of the expelled oil. The necessary pressure increase to expel oil and fluids is obtained by a cone partly obstructed at the screw head. In this type of press, pressures rise up to $110 \mathrm{MPa}$ and minimum oil content of the order of 3.5\% can be obtained [3].

- Expanders and twin-screw extruders have dedicated applications. The first is used for pre-treatment or expression of lowoil content material (soybeans) and the second has the major advantage of skipping the pre-treatment steps, depending on the screw configurations. However, expression by twin-screw extruders has not yet transferred to the scale of industrial processes.

- Twin-screw extruders play an important role in transforming the material physically and chemically in a single step. This process seems to be most used in preparing samples for analysis, so we present a more precise mode of operation for this technique. A twin-screw extruder is based on: a conveying action realized by forward pitch screw, and radial compression and shearing actions by Monolobe screw. Bilobe, which exerts a significant mixing and shearing action, conveying and axial compression actions in combination with forward pitch screw, and reversed pitch screw, which carries out intensive shearing and considerable mixing, and exerts strong axial compression in combination with a forward pitch screw [4].

The choice of these characteristics of screw elements, in position or spacing (pitch, stagger angle, length), determines the screw profile or configuration (Fig. 4). The performance is mainly influenced by these configuration arrangements (product transformation, residence time distribution, and mechanical energy input) during extrusion processing. In theory, the operation of a screw press and the hydraulic press operating horizontally are comparable. The necessary compression for liquid exudation (metabolites) is due to the formation of the plug, which is generated by gradually reducing the volume available along the press. These pressures are the result of two forces applied on the seed mass:

- radial (thrust on the cage); and,

- axial (taking forward the matter in the press) [5-8].

\subsection{Applications}

Pressing for solvent-free extraction is used in a great number of industrial applications in the food domain, for example:

- juice extraction from grapes, fruit, and tomatoes;

- oil extraction (olives, cocoa butter, oleaginous seeds);

- concentrate in dry matter (sugar pulps, sludge, wastes from food industry).

- separation of the serum from curd in cheese manufacturing.

The combination of pressing with other processes can be studied in a research context, in order to obtain better extracts (quality and quantity versus time) at the stage of process intensification. For example, De Haan et al. [9,10] introduced gas-assisted mechanical expression (GAME) to increase oil-extraction yield and to reduce the effective mechanical pressure applied on the seeds using $\mathrm{CO}_{2}$ assistance. New research work \{e.g., Mhemdi et al. [11]\} investigated the pre-treatment of sugar beets with PEF to facilitate the expression process. The feasibility of the pressing process in preparing samples has been investigated on different matrices (Table 1).

Monrad et al. [12] have studied extraction of anthocyanins and flavan-3-ols from red-grape pomace using an expeller process. This work demonstrated that this process allowed extraction of $68 \%$ of the monomeric anthocyanins for crude and $41 \%$ with dried samples, extraction of total flavan-3-ols are $58 \%$ and $38 \%$, respectively, and enhancements of antioxidant activities by ORAC assay were $58 \%$ and $38 \%$ compared with those obtained with extracts from conventional procedures.

Celhay et al. [13] used a twin-screw extractor to realize extraction of polyphenols from a wood by-product. The extracts, due to their polyphenolic content and their high antioxidant activity, can be used, e.g., as high-value substances for food and health applications. 
Version définitive du manuscrit publiée dans / Final version of the manuscript published in :

Trends in Analytical Chemistry (2015), Vol. 71, p. 157-168, DOI: 10.1016/j.trac.2015.02.021

Journal homepage : http://www.elsevier.com/locate/trac

\section{Instant controlled pressure drop}

\subsection{Principle}

DIC was developed by Allaf et al. [19], based on the main principle of the thermodynamics of instantaneity. DIC treatment can be used to expand different materials by an appropriate autovaporization that depends on the amount of vapor generated, the internal pressure constraints, the pressure-drop rate, and the viscoelastic behavior of the material. DIC is classified as a hightemperature short-time (HTST) process and consists of thermomechanical processing induced by subjecting the product to a fast transition from high steam pressure to vacuum.

The two main steps of DIC extraction are usually a heating step, followed by an abrupt pressure drop towards a vacuum (about $5 \mathrm{kPa}$ with a rate higher than $0.5 \mathrm{MPa} / \mathrm{s}$ ). Indeed, the sample, whose water content is generally adjusted to about 30\% dry basis, is subjected to heating under high pressure (up to $1 \mathrm{MPa}$ ) at high temperature (up to $180^{\circ} \mathrm{C}$ ) for a short time (5-60 s). A pressure drop is applied in the treatment vessel after this pre-conditioning heating and homogenization stage. By abruptly reducing the pressure, instant auto-vaporization of the moisture inside the material will occur. Several physical modifications of the sample are due to this rapid depressurization: auto-vaporization of water and volatile or non-volatile compounds contained in the sample, an instantaneous cooling of the sample, and swelling and even rupture of cells, and secretion of metabolites through cell walls. These physical modifications lead to texture change, which results in higher porosity, increased specific, surface area and reduced diffusion resistance.

\subsection{Process and procedure}

There are four major components in the DIC reactor (Fig. 5):

(1) processing extraction vessel, which is an autoclave with a heating jacket where samples are placed and treated;

(2) instantaneous pressure valve, which ensures a controlled liberation of pressure contained in the extraction vessel to the vacuum tank;

(3) vacuum system, which consists mainly of a vacuum tank with a volume 50 times greater than the processing vessel; the vacuum tank is cooled through a double jacket for condensation of the extracts; and,

(4) condensate is recuperated through a trap; a water ring pump maintains the tank pressure at about $5 \mathrm{kPa}$.

When steam is used as heating fluid, the heat transfer in vegetal material is enhanced by the initial vacuum, which assures closer contact of heat with the exchange surface. After closing the valve, the autoclave is filled with steam up to a processing pressure. An abrupt pressure drop within the autoclave is obtained after a certain time at a fixed processing pressure by instantaneously opening the pneumatic valve (less than $0.2 \mathrm{~s}$ ). Just after the vacuum is reached, the instant valve is closed and the atmospheric pressure is reached. A specific vessel placed under the vacuum tank retains the emulsion of condensed steam and extracted metabolites.

A multi-cycle DIC process comprises a number of cycles, each containing repetition of the stages of heating/homogenization and pressure-drop towards a vacuum. Each following cycle ( $i>1)$ is performed by directly injecting steam after the vacuum stage of the
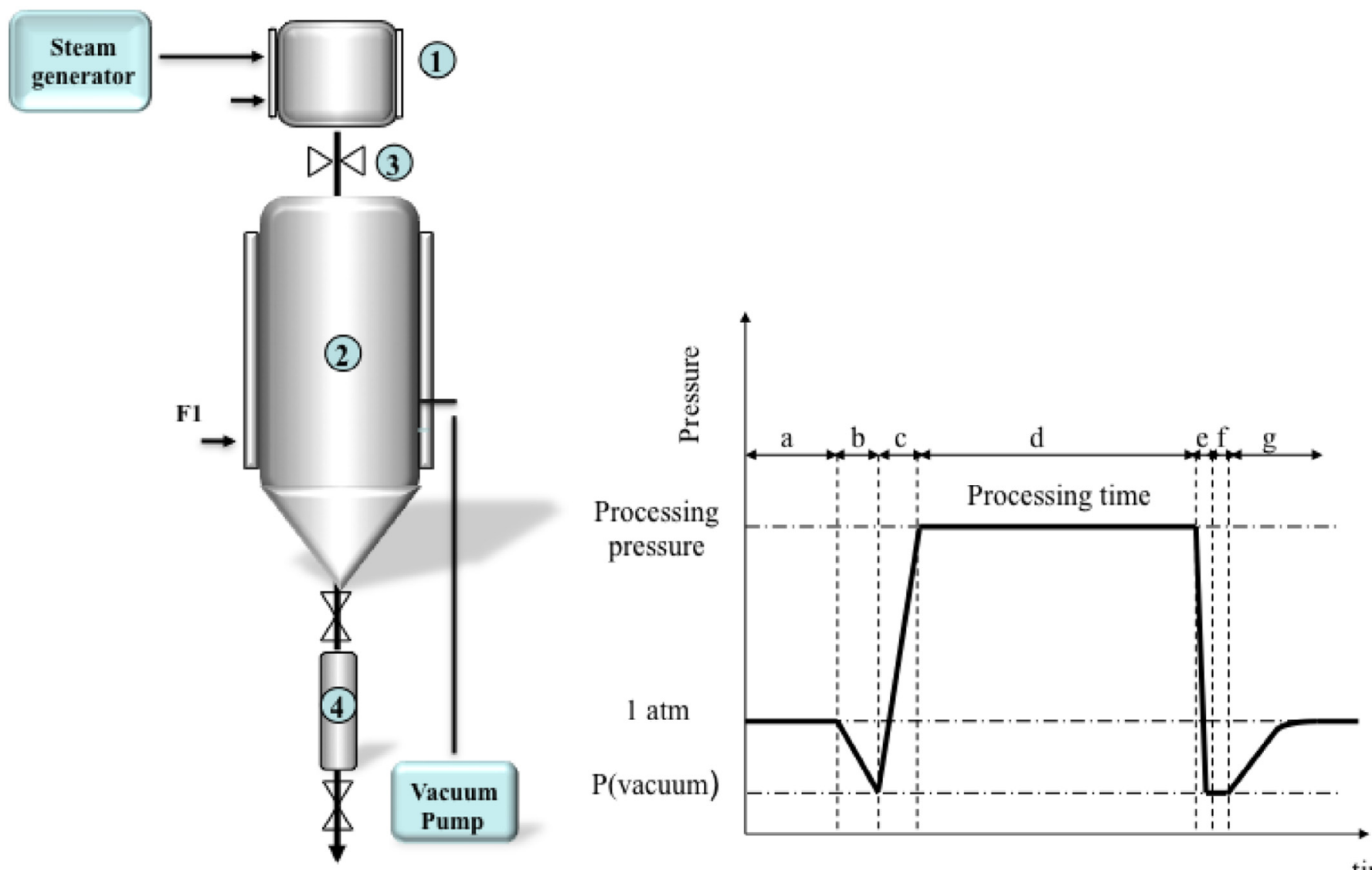

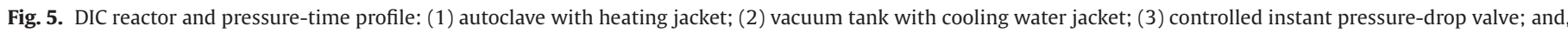
(4) extract container. 
Version définitive du manuscrit publiée dans / Final version of the manuscript published in :

Trends in Analytical Chemistry (2015), Vol. 71, p. 157-168, DOI: 10.1016/j.trac.2015.02.021

\section{Journal homepage : http://www.elsevier.com/locate/trac}

previous cycle (i-1) without release towards the atmospheric pressure. The last cycle $(i=n)$ is finished by the release-to-atmosphere stage. The total heating time is the heating time of all cycles ( $\mathrm{n} x$ $\mathrm{d})$, where $\mathrm{d}$ is the heating time of each cycle, which is slightly less than the total processing time.

\subsection{Industrial applications}

The preparation of different samples by the DIC process was investigated on different matrices (Table 2). DIC-assisted extraction of anthocyanins from Roselle calyces was studied by Benamor et al. [25], who demonstrated that extraction kinetics and yields of these compounds were increased by the DIC process. They also noticed the impact of DIC treatment on extraction of oligosaccharides (stachyose and ciceritol) from the seeds of the Indian Tephrosia purpurea plant [27]. Compared to extraction where the sample was not pre-treated by DIC, an improvement of solid-fluid extraction of the compound of interest was shown in these studies. The DIC process can also be used for the extraction of polyphenols, such as diterpens (carnosic acid) and phenolic acids (rosmarinic acid) from rosemary leaves, to illustrate the bio-refinery concept [24].

Indeed, since DIC treatment is a perfectly controlled process, its operating parameters can be optimized in order to modify, partly or completely, the organization of the raw material tissue, depending on solvent-extraction requirements. DIC has also been used for the extraction of essential oils from various plants, such as orange peel [20], myrtle leaves [21], and lavender flowers [22]. The main advantages are:

(1) no solvent is used;

(2) short time of contact of essential oil and secondary metabolites with heating zones to avoid thermal degradation; and,

(3) an abrupt pressure variation, which allows a rapid release of essential oils by instant autovaporization coupled to dramatically effective Darcy-type internal transfer of essential oil vapors.

In some cases, DIC can trigger the rupture of the oil-containing glands. These aspects together allow increasing kinetics, yields and final product quality compared to other processes for extracting essential oils [23]. The effectiveness of this operation is mainly due to the number of DIC cycles, and the processing temperature. It slightly depends on processing time. By optimizing DIC operating parameters, the duration required to reach maximum extraction yield

Table 2

Examples of applications and experimental conditions of DIC

\begin{tabular}{lllll}
\hline Matrix & Analytes & $\begin{array}{l}\text { Experimental } \\
\text { conditions }\end{array}$ & $\begin{array}{l}\text { Analysis and } \\
\text { detection }\end{array}$ & Ref. \\
\hline Orange peel & Essential oil & $\begin{array}{l}0.6 \mathrm{mPa}, 152 \mathrm{~s}, \\
11 \mathrm{cycles}\end{array}$ & GC-FID, GC-MS & {$[20]$} \\
Myrtle leaves & Essential oil & $\begin{array}{l}0.6 \mathrm{mPa}, 120 \mathrm{~s}, \\
4 \text { cycles }\end{array}$ & GC-FID, GC-MS & {$[21]$} \\
Lavender flowers & Essential oil & $\begin{array}{l}0.6 \mathrm{mPa}, 240 \mathrm{~s}, \\
6 \text { cycles }\end{array}$ & GC-FID, GC-MS & {$[22]$} \\
Angelica seeds & Essential oil & $\begin{array}{l}0.6 \mathrm{mPa}, 120 \mathrm{~s}, \\
4 \mathrm{cycles}\end{array}$ & GC-FID, GC-MS & {$[21]$} \\
Rosemary leaves & Essential oil & $\begin{array}{l}0.6 \mathrm{mPa}, 300 \mathrm{~s}, \\
1 \mathrm{cycles}\end{array}$ & GC-FID, GC-MS & {$[23]$} \\
Rosemary leaves & Polyphenol & $\begin{array}{l}0.6 \mathrm{mPa}, 180 \mathrm{~s}, \\
11 \mathrm{cycles}\end{array}$ & UV-visible, HPLC & {$[24]$} \\
Roselle & Anthocyanins & $\begin{array}{l}0.18 \mathrm{mPa}, 20 \mathrm{~s}, \\
1 \mathrm{cycles}\end{array}$ & UV-Visible, HPLC & {$[25]$} \\
Soybeans & Edible oil & $\begin{array}{l}0.3 \mathrm{mPa}, 60 \mathrm{~s}, \\
1 \mathrm{cycles}\end{array}$ & GC-FID, GC-MS & {$[26]$} \\
Tephrosia seeds & Ciceritol & $\begin{array}{l}0.6 \mathrm{mPa}, 240 \mathrm{~s}, \\
1 \mathrm{cycles}\end{array}$ & HPLC-DAD & {$[27]$} \\
\hline
\end{tabular}

really is better [ $60-240 \mathrm{~s}$, whereas it takes more than $3 \mathrm{~h}$ to reach similar yield with hydro-distillation (HD)].

In solvent extraction [e.g., water, or supercritical $\left.\mathrm{CO}_{2}\left(\mathrm{SC}-\mathrm{CO}_{2}\right)\right]$, authors used DIC as a pre-treatment process. For example, DIC pretreatment prior to supercritical $\mathrm{CO}_{2}$ extraction was used by Rochova et al. [26]. It increased the extraction rate by reducing the process time (several minutes versus several hours), and possibly increased yield, which was comparable to or even higher than conventional $\mathrm{SC}-\mathrm{CO}_{2}$ extraction. In terms of quality, DIC systematically obtained higher quality essential oils, as revealed by the higher content of oxygenated compounds. Finally, DIC use implies reducing the amount of solvent (about $25 \%$ of that required with material without DIC).

\subsubsection{Scaling up industrial units for food}

DIC treatment is usually defined as a short-time operation, requiring a processing time of 5-60 s, depending on the raw material and the objectives. Thus, large-capacity industrial DIC equipment has been defined as normally implying a relatively small-volume treatment vessel.

The second specificity of DIC treatment is the similarity of the operating parameters (i.e., pressure, temperature, heating time, vacuum level and pressure drop rate, initial water content, etc.) whatever the scale.

The third specificity of DIC treatment concerns the vacuum level, usually 3-5 $\mathrm{kPa}$, which implies using low-cost equipment, such as a liquid-ring vacuum pump. Other aspects enable the whole equipment manufacturing to be simplified. Thus, the vacuum tank can have various shapes and forms and be positioned at some distance from the treatment vessel. The whole operation can be completely automated.

\subsubsection{Scaling down with cosmetic or pharmaceutical units}

Cosmetic and pharmaceutical ingredients are increasingly required to be based on natural plants instead of chemical compounds manufactured synthetically, so various green extraction processes [e.g., solvent-free processes, $\mathrm{SC}-\mathrm{CO}_{2}$ extraction, and ultrasound (US)assisted extraction] were defined in order to reduce both energy consumption and environmental impact. For all these extraction processes, particle size has a great impact on yields and kinetics. The lower the granulometry, the easier the extraction process in terms of both yields and kinetics.

However, natural-plant tissues and structures are well known as inadequate for easily expelling or extracting internal compounds. Cell membranes and cell walls are too hard to allow transport of these compounds towards the surrounding medium. By using adequate operating parameters, DIC allows the plant to attain higher porosity and lower tortuosity, and can even lead to disruption of cell membranes and cell walls. Thus, appropriately optimized DIC treatment permits dramatic intensification of each of these conventional or innovative extraction processes in terms of process performance and extract quality. These shorter time/higher yield operations allow smallsized, high-capacity DIC units, which are very convenient and useful in the cosmetic and pharmaceutical industries.

\subsubsection{Scaling down and biochemical assessment through micro-DIC units}

As explained in the previous paragraph, it is normally too difficult to assess the composition of any plant organ, such as fruits, leaves, roots, and vegetables. Although various operations of grinding are systematically used as pretreatment for different spectrometric or chromatographic measurements, the amount of compound required would systematically be underestimated, and this limits the assessment efficiency, whatever the method being considered. Some pretreatment methods, such as French-Press, can shear the cells and disrupt the cell-wall structure. Such an operation 

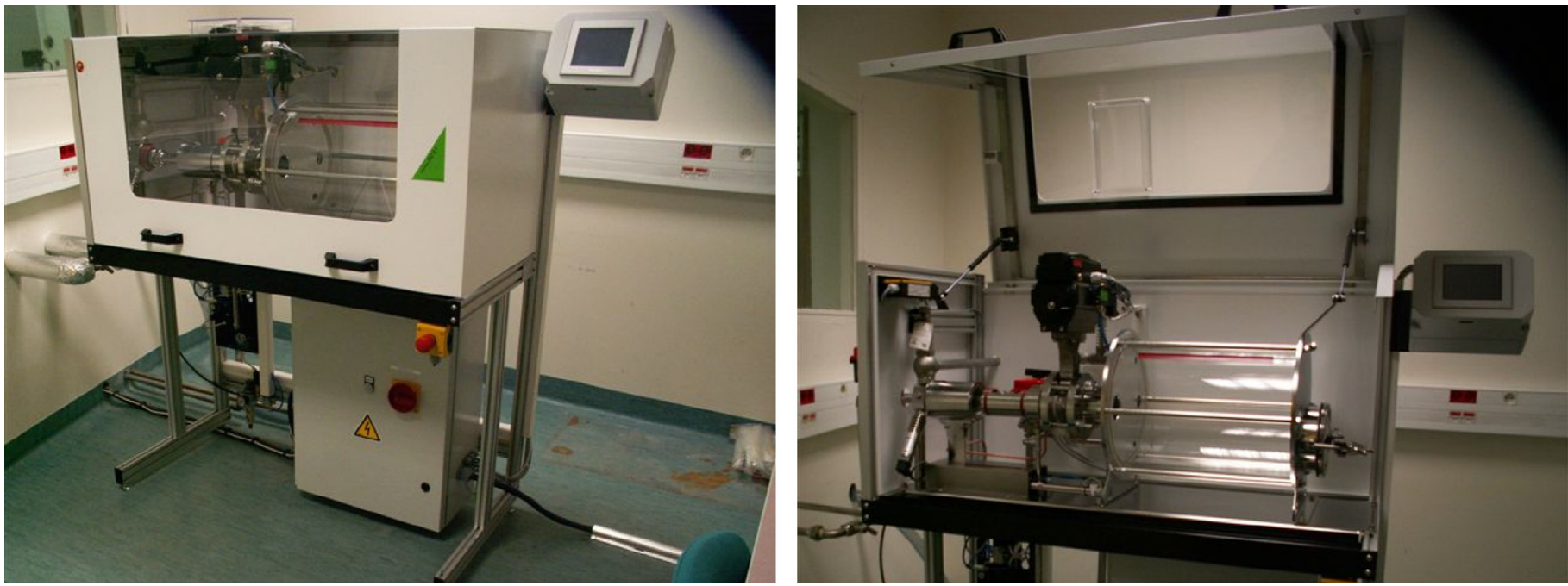

Fig. 6. Downscaling of DIC.

used as pretreatment can open these strongboxes of cells to make their contents more available and make the determination of the composition more realistic. A similar situation can be achieved using DIC treatment. However, DIC can be applied for almost all plant organs, while the French-Press system is appropriate for only pumpable systems (e.g., liquid solution).

A micro-DIC unit with a $30-\mathrm{mL}$ treatment vessel was designed and manufactured by ABCAR-DIC Process (La Rochelle, France). It could be inserted within an suitable spectrometer or chromatograph (Fig. 6).

\section{Solvent -free microwave extraction}

\subsection{Principle}

MWs are electromagnetic waves with a frequency range of 0.1-3 $\mathrm{GHz}$. MWs comprise electric and magnetic field components in propagating electromagnetic energy, which acts as non-ionizing radiation that causes molecular motions of ions and rotation of the dipoles, but does not affect molecular structure. When dielectric materials containing permanent or induced dipoles are placed in a MW field, the rotation of the dipoles in the alternating field produces heat. More precisely, the applied MW field causes the molecules, on average, to spend slightly more time orienting themselves in the direction of the electric field rather than in other directions. When the electric field is removed, thermal agitation returns the molecules to a disordered state in the relaxation time, and thermal energy is released. Thus, MW heating results from the dissipation of the electromagnetic waves in the irradiated medium. The power dissipated in the medium depends on the complex permittivity of the material and the local time-averaged electric-field strength.

MWs provide a non-contact heat source, which can not only make heating more effective and selective, but also help to accelerate energy transfer, start-up and response to heating control, and to reduce thermal gradient, equipment size and operation units. Solvent-free MW extraction (SFME) is a key sustainable technology in achieving the objective of green chemistry. It has been rapidly developed as one of the attractive techniques to extract and to separate interesting high added-value compounds from solid samples. With the help of MWs, extraction can now be completed without solvents in minutes instead of hours with various advantages (e.g., high reproducibility, less energy consumption, shorter procedures, and higher purity of the final product). Several classes of compounds, such as essential oils, antioxidants, pigments, aromas, and other organic compounds, have been separated efficiently from a variety of raw materials, in particular from natural-plant resources [28].

The simplest, most innovative SFME technique is MW hydrodiffusion and gravity (MHG), which is an original "upside down" alembic combining MW heating and Earth gravity at atmospheric pressure [29]. MHG was conceived for laboratory applications in the extraction of pigments, aroma components, and antioxidants from different kinds of plant. The simple principle of this technique consists of placing plant material inside a MW reactor, without adding any solvent or water. Heating the internal water within the plant material allows the destruction of plant cells containing bioactive components. All the possible extracts, including the internal water of the plant, will be released and transferred from inside to outside the plant material. This is the physical hydrodiffusion phenomenon, which allows the extracts to drop out of the MW reactor under the effect of Earth gravity and to fall into a cooling system outside the MW oven through the perforated Pyrex disc, where the extracts are continuously condensed. The crude extracts are collected in a receiving flask for further analysis (Fig. 6).

The MHG system was modified by introducing vacuum created by a vacuum pump, which is fitted between the condenser and the flask used to collect the natural-plant extracts. The crude extracts are collected and freeze-dried before further analysis [30]. It is important to note that this green method allows extraction of bioactive components without distillation and evaporation, which are the most energy-consuming processes of the unit operations. MHG is not a modified MW-assisted extraction that uses organic solvents, an SFME that evaporates the bioactive extracts with in situ water, or a modified hydrodistillation that uses a large quantity of water and energy consumption.

\subsection{Process and procedure}

An open vessel multimode MW extractor (NEOS-GR, Milestone Srl, Italy) operating at $2.45 \mathrm{GHz}$ and maximum power of $900 \mathrm{~W}$, with a 1.5-L Pyrex extraction vessel was used to perform MHG extraction (Fig. 7). During the solvent-free extraction experiments, temperature was monitored by an external infrared (IR) sensor. 
Version définitive du manuscrit publiée dans / Final version of the manuscript published in :

Trends in Analytical Chemistry (2015), Vol. 71, p. 157-168, DOI: 10.1016/j.trac.2015.02.021

Journal homepage : http://www.elsevier.com/locate/trac
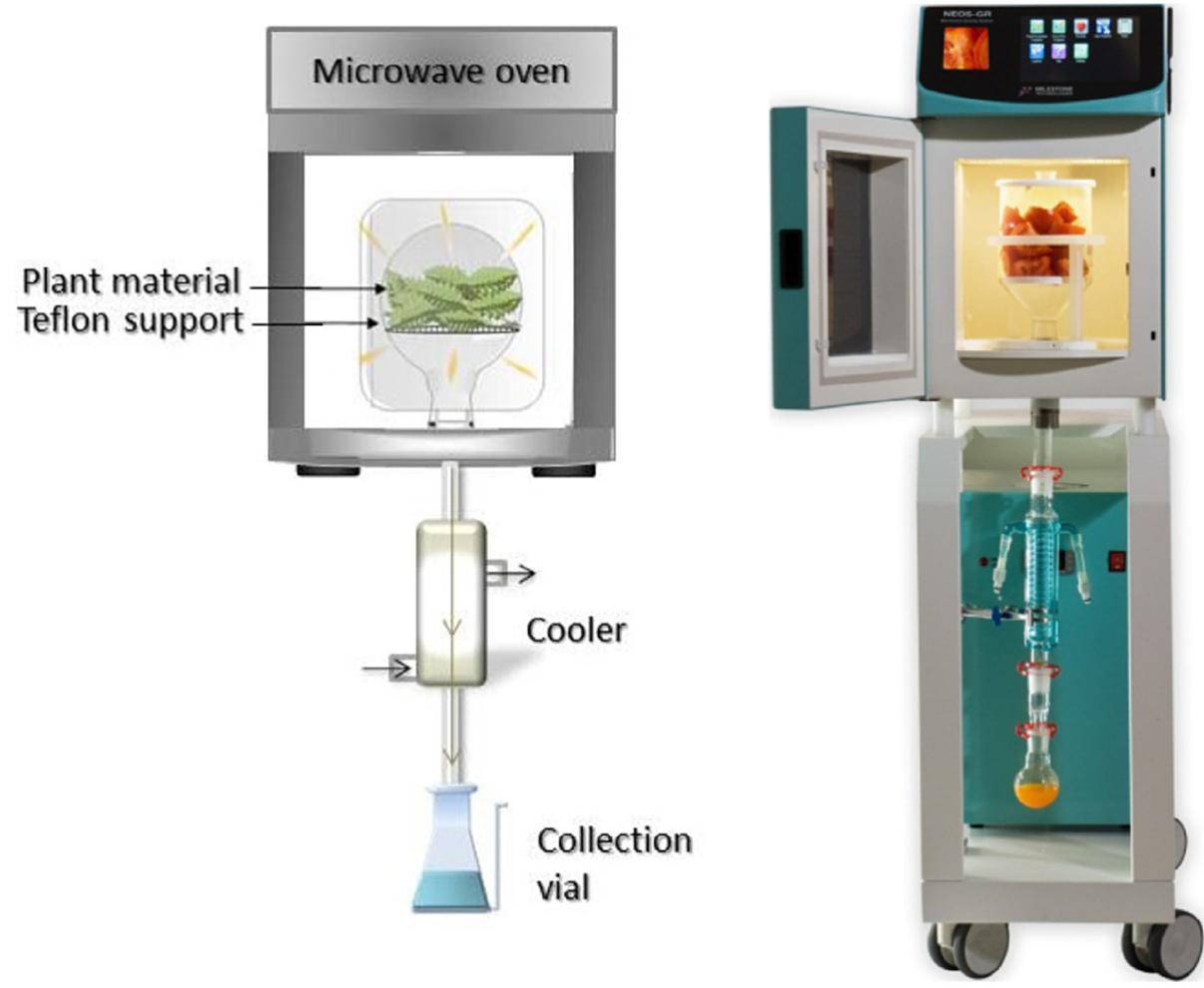

Fig. 7. Solvent-free microwave extraction using microwave hydro-diffusion and gravity.

\subsection{Applications}

The feasibility of the MHG process in preparing samples was investigated for different matrices, as shown in Table 3. This process was applied to many kinds of plants, such as aromatic plants and citrus plants for an essential-oil extraction [30-32].

The first example is Mentha pulegium L. extraction [30], where $0.95 \%$ of essential oil was obtained by heating $500 \mathrm{~g}$ of matrix at $500 \mathrm{~W}$ for $20 \mathrm{~min}$ at atmospheric pressure. The essential oils of $M$. spicata L. and M. pulegium L. extracted by MHG or HD were rather similar in their composition. The same number of volatile secondary metabolites was found in the essential oils isolated by MHG or $\mathrm{HD}$, with similar yields. Identification of the EO components was carried out by GC-MS and quantitated by a GC coupled to a flameionization detection (FID) system.

For Citrus limon (L.) [31], a MW irradiation power of $500 \mathrm{~W}$ for $500 \mathrm{~g}$ of plant material was chosen as an optimum for only $15 \mathrm{~min}$ to extract the essential oil completely. MHG is clearly quicker than conventional HD; an extraction time of 15 min with MHG provided yields comparable to those obtained after 180 min by HD, which is the one of the reference methods in essential-oil extraction. The overall yield of essential oil obtained from lime peels was $1.0 \pm 0.1 \%$ and $1.1 \pm 0.1 \%$ by MHG and HD, respectively. In this application, MW irradiation greatly accelerated the extraction process, but without causing considerable changes in the volatile-oil composition.

Another example with Rosmarinus officinalis L. [32] was tested, and the yields of rosemary essential oil with the different isolation methods were $0.35 \pm 0.07 \%$ and $0.33 \pm 0.09 \%$ for HD and MHG, respectively. In this case, slightly greater amounts of oxygenated compounds were present in the essential oils of the aromatic plant isolated by MHG than by HD, so MHG offers the possibility for a better reproduction of natural aroma of the essential oil from rosemary leaves than the HD. Moreover, the MW procedure yielded essential oils that could be analyzed or used directly without any clean-up, solvent-exchange or centrifugation steps.

This innovative technique was also applied to the extraction of antioxidant compounds. Zill-e-Huma et al. [33,34] reported MHG for extracting flavonoids from onion. The plant tissues were strongly disrupted by MW irradiation, as seen through the microscopic observation of extracts, so that target compounds could be efficiently extracted and detected by HPLC and other

Table 3

Examples of applications and experimental conditions of SFME

\begin{tabular}{|c|c|c|c|c|}
\hline Matrix & Analytes & Experimental conditions & Analysis and detection & Ref. \\
\hline $\begin{array}{l}\text { Mint } \\
\text { Mentha spicata L., Mentha pulegium } L .\end{array}$ & Essential oil & P.atm, $500 \mathrm{~W}, 20 \mathrm{~min}$ & GC-MS/GC-FID & {$[30]$} \\
\hline $\begin{array}{l}\text { Rosemary leaves } \\
\text { Rosmarinus officinalis } L \text {. }\end{array}$ & Essential oil & P.atm, $500 \mathrm{~W}, 15 \mathrm{~min}$ & GC-MS/GC-FID & {$[31]$} \\
\hline Citrus peel & Essential oil & P.atm, $500 \mathrm{~W}, 15 \mathrm{~min}$ & GC-MS/GC-FID & {$[32]$} \\
\hline $\begin{array}{l}\text { Onion } \\
\text { Allium cepa } L \text {. }\end{array}$ & Polyphenols & P.atm, $500 \mathrm{~W}, 30 \mathrm{~min}$ & HPLC-DAD & [33] \\
\hline Red, yellow, white and grelot onion & Polyphenols & P.atm, $500 \mathrm{~W}, 30 \mathrm{~min}$ & HPLC-DAD & {$[34]$} \\
\hline $\begin{array}{l}\text { Sea buckthorn } \\
\text { Hippophae rhamnoides }\end{array}$ & Polyphenols & P.atm, $400 \mathrm{~W}, 15 \mathrm{~min}$ & HPLC-DAD & [35] \\
\hline
\end{tabular}


Version définitive du manuscrit publiée dans / Final version of the manuscript published in :

Trends in Analytical Chemistry (2015), Vol. 71, p. 157-168, DOI: 10.1016/j.trac.2015.02.021

Journal homepage : http://www.elsevier.com/locate/trac

Table 4

Examples of applications and experimental conditions of PEF

\begin{tabular}{|c|c|c|c|c|}
\hline Matrix & Analytes & Experimental conditions & Analysis and detection & Ref. \\
\hline Grape & Anthocyanins & $3 \mathrm{kV} / \mathrm{cm}, 30$ pulses, $70^{\circ} \mathrm{C}$, ethanol and water & LC-DAD/ESI-MS & {$[38]$} \\
\hline Red cabbage & Anthocyanins & $2.5 \mathrm{kV} / \mathrm{cm}, 50$ pulses & HPLC-MS & [39] \\
\hline Purple-fleshed potato & Anthocyanins & $3.4 \mathrm{kV} / \mathrm{cm}, 35$ pulses, $10-40^{\circ} \mathrm{C}$, ethanol and water & HPLC-DAD & {$[40]$} \\
\hline Grape seeds & Polyphenols & $8-20 \mathrm{kV} / \mathrm{cm}, 0-20 \mathrm{~ms}, 50^{\circ} \mathrm{C}$, ethanol & UV-Visible spectroscopy & [41] \\
\hline Sugar beet & Sucrose & $7 \mathrm{kV} / \mathrm{cm}, 20$ pulses, $40^{\circ} \mathrm{C}, 60 \mathrm{~min}$ & Refractometry & {$[42]$} \\
\hline Red beet & Betalains & $0.375-1.5 \mathrm{kV} / \mathrm{cm}, 100-\mu$ s pulses, $30-80^{\circ} \mathrm{C}$, water & UV-Visible spectroscopy & [43] \\
\hline
\end{tabular}

\{e.g., polyphenols from a large number of fruits, vegetables and agricultural waste [38-41], sucrose from the sugar beet [42], and betalains from red beets [43]\}. These references provide a brief overview of the many applications of PEF-assisted extraction of valuable compounds from natural products (Table 4).

PEF has mainly been used to extract polyphenols \{e.g., recovery from grape seeds [41]\}. The PEF efficiency was improved when the treatment was performed at $50^{\circ} \mathrm{C}$ in the presence of ethanol. PEF pre-treatment increased both the extraction kinetics and the maximum yield of polyphenols. The final content of polyphenols was $9 \mathrm{~g} \mathrm{GAE} / 100 \mathrm{~g}$ DM after 15 min extraction.

Corrales [38] compared extraction of anthocyanins from grape by-products using ultrasonics, high hydrostatic pressure (HHP) and PEF, and reported an improvement of $10 \%$ in extraction compared to HHP and $17 \%$ more compared to conventional extraction, with the least increase being observed with ultrasonics. They used an electric-field strength of $3 \mathrm{kV} / \mathrm{cm}$ and 30 pulses and further extraction was carried out at $70^{\circ} \mathrm{C}$ using ethanol and water solvents.

Anthocyanins were also extracted from red cabbage by PEF treatment [39]. These authors showed that PEF treatment enhanced total extraction of anthocyanins in water 2.15 times with a higher proportion of non-acylated forms than control.

In a recent study [40], PEF treatment was used for anthocyanin extraction from purple-fleshed potato at different extraction times $(60-480 \mathrm{~min})$ and temperatures $\left(10-40^{\circ} \mathrm{C}\right)$ using water and ethanol as solvents (48\% and $96 \%$, respectively). A PEF treatment of $3.4 \mathrm{kV} / \mathrm{cm}$ and $105 \mu \mathrm{s}$ ( 35 pulses of $3 \mu \mathrm{s}$ ) resulted in the highest celldisintegration index at the lowest specific energy requirements $(8.92 \mathrm{~kJ} / \mathrm{kg})$. This PEF treatment increased the anthocyanin extraction yield, the effect being higher at the lower extraction temperature with water as solvent.

Lopez et al. [41] showed PEF as a suitable pre-treatment before the extraction of sugar beets in order to reduce the extracting temperature, the time and the energy requirements over traditional thermal extraction. A treatment of 20 pulses at $7 \mathrm{kV} / \mathrm{cm}(3.9 \mathrm{~kJ} / \mathrm{kg})$ reduced the temperature for $80 \%$ extraction of sucrose from $70^{\circ} \mathrm{C}$ to $40^{\circ} \mathrm{C}$ in a 60 -min extraction process.

PEF treatments proved to enhance betalain extraction efficiency with relatively low levels of tissue damage and low energy consumption. PEF treatment, using trains of monopolar rectangular $100 \mu$ s pulses with electric-field strength $E=375-1500 \mathrm{~V} / \mathrm{cm}$, and total treatment time $t_{\mathrm{PEF}}=0-0.2 \mathrm{~s}$, was found effective for accelerating the extraction of betalains and reducing the time of extraction [43].

\section{Conclusion and future trends}

In this review, we discussed how the concept of solvent-free extraction has become an important issue in the chemistry of natural products. Detailed analysis of past and present literature explicitly confirms the usefulness of "original" methods of solvent-free extraction. The understanding, on the molecular scale, of processes relevant to solvent-free extraction techniques has not yet reached the degree of maturity of other topics in analytical chemistry. Such a challenge is somewhat ambitious and requires a special approach. We hope that this review will widen the scope of laboratory and commercial success for the potential applications of solvent-free extraction in food and natural-product chemistry.

\section{References}

[1] S. Armenta, S. Garrigues, M. de la Guardia, Green analytical chemistry, Trends Analyt. Chem. 27 (2008) 497-511.

[2] F. Chemat, M. Abert-Vian, G. Cravotto, Green extraction of natural products: concept and principles, Int. J. Mol. Sci. 13 (2012) 8615-8627.

[3] H.G. Schwartzberg, Expression of fluid from biological solids, Sep. Purif. Methods 26 (1997) 1-213.

[4] R. Savoire, J.-L. Lenoisellé, E. Vorobiev, Mechanical continuous oil expression from oilseeds: a review, Food Bioprocess Technol. 6 (2012) 1-16.

[5] B.K. Gogoi, G.S. Choudhury, A.J. Oswalt, Effects of location and spacing of reverse screw and kneading element combination during twin-screw extrusion of starchy and proteinaceous blends, Food Res. Int. 29 (1996) 505-512.

[6] G.S. Chaudhury, B.K. Gogoi, A.J. Oswalt, J. Aquat, Twin-screw extrusion pink salmon muscle and rice flour blends: effects of kneading elements, Food Prod. Technol. 7 (1998) 69-91.

[7] I. Amalia Kartika, P.Y. Pontalier, L. Rigal, Oil extraction of oleic sunflower seeds by twin screw extruder: influence of screw configuration and operating conditions, Ind. Crops Prod. 22 (2005) 207-222.

[8] I. Amalia Kartika, P.Y. Pontalier, L. Rigal, Extraction of sunflower oil by twin screw extruder: screw configuration and operating condition effects, Bioresour. Technol. 97 (2006) 2302-2310.

[9] M. Venter, P. Willems, N. Kuipers, A.B. De Hann, Gas assisted mechanical expression of cocoa butter from cocoa nibs and edible oils from oilseeds, J. Supercrit. Fluid. 37 (2006) 350-358.

[10] P. Williems, N.J.M. Kuipers, A.B. De Haan, Gas assisted mechanical expression of oilseeds: influence of process parameters on oil yield, J. Supercrit. Fluid. 45 (2008) 298-305.

[11] H. Mhemdi, O. Bals, N. Grimi, E. Vorobiev, Filtration diffusivity and expression behaviour of thermally and electrically pretreated sugar beet tissue and press-cake, Sep. Purif. Technol. 95 (2012) 118-125.

[12] J.K. Monrad, M. Suarez, M.J. Motilva, J.W. King, K. Srinivas, L.R. Howard, Extraction of anthocyanins and flavan-3-ols from red grape pomace continuously by coupling hot water extraction with a modified expeller, Food Res. Int. 65 (2014) 77-87.

[13] C. Celhay, C.E. Mathieu, L. Candy, G. Vilarem, L. Rigal, Aqueous extraction of polyphenols and antiradicals from wood by-products by a twin-screw extractor: feasibility study, CRC Chimie 17 (2014) 204-211.

[14] F. Pinto, M. de Abreu, A.P. Dornier, M. Dionisio, C. Carail, C. Caris-Veyrat, Dhuique-Mayer, Cashew apple Anacardium occidentale L. extract from byproduct of juice processing: a focus on carotenoids, Food Chem. 138 (2013) 25-31.

[15] I. Amalia Kartika, P.Y. Pontalier, L. Rigal, Twin-screw extruder for oil processing of sunflower seeds: thermo-mechanical pressing and solvent extraction in a single step, Ind. Crops Prod. 32 (2010) 297-304.

[16] S. Sayasoonthorn, S. Kaewrueng, P. Patharasathapornkul, Rice bran oil extraction by screw press method: optimum operating settings, oil extraction level and press cake appearance, Rice Sci. 19 (2012) 75-78.

[17] R.C. Pradhan, S. Mishra, S.N. Naik, N. Bhatnagar, V.K. Vijay, Oil expression from Jatropha seeds using a screw press expeller, Biosyst. Eng. 109 (2011) 158-166.

[18] D. Labuckas, D. Maestri, A. Lamarque, Effect of different oil extraction methods on proximate composition and protein characteristics of walnut Juglans regia L. flour, LWT - Food Sci. Technol. 1 (2014) 794-799.

[19] T. Allaf, K. Allaf, Instant Controlled Pressure Drop (D.I.C.) in Food Processing, Springer, NewYork, 2014.

[20] T. Allaf, V. Tomao, C. Besombes, F. Chemat, Thermal and mechanical intensification of essential oil extraction from orange peel via instant autovaporization, Chem. Eng. Proc. 72 (2013) 24-30.

[21] B. Berka-Zougali, A. Hassani, C. Besombes, K. Allaf, Extraction of essential oils from Algerian myrtle leaves using instant controlled pressure drop technology, J. Chromatogr. A 1217 (2010) 6134-6142.

[22] C. Besombes, B. Berka-Zougali, K. Allaf, Instant controlled pressure drop extraction of lavandin essential oils: fundamentals and experimental studies, J. Chromatogr. A 1212 (2010) 6807-6815. 
Version définitive du manuscrit publiée dans / Final version of the manuscript published in :

Trends in Analytical Chemistry (2015), Vol. 71, p. 157-168, DOI: 10.1016/j.trac.2015.02.021

Journal homepage : http://www.elsevier.com/locate/trac

[23] S.A. Rezzioug, C. Boutekedjiret, K. Allaf, Optimization of operating conditions of rosemary essential oil extraction by a fast controlled pressure drop process using response surface methodology, J. Food Eng. 71 (2005) 9-17.

[24] T. Allaf, V. Tomao, K. Ruiz, K. Bachari, M. ElMaataoui, F. Chemat, Deodorization by instant controlled pressure drop autovaporization of rosemary leaves prior to solvent extraction of antioxidants, LWT - Food Sci. Technol. 51 (2013) 111-119.

[25] B. Benamor, K. Allaf, Impact of texturing using instant pressure drop treatment prior to solvent extraction of anthocyanins from Malaysian Roselle (Hibiscus sabdariffa), Food Chem. 115 (2009) 820-825.

[26] K. Rochova, H. Sovova, V. Dobolik, K. Allaf, Impact of seed structure modification on the rate of supercritical $\mathrm{CO}_{2}$ extraction, J. Supercrit. Fluid. 44 (2008) 211-218.

[27] B. Benamor, C. Lamy, P. Andre, K. Allaf, Effect of instant controlled pressure drop treatments on the oligosaccharides extractability and microstructure of Tephrosia purpureaseeds, J. Chromatogr. A 1213 (2008) 118-124.

[28] Y. Li, A.S. Fabiano-Tixier, M. Abert Vian, F. Chemat, Solvent-free microwave extraction of bioactive compounds provides a tool for green analytical chemistry, Trends Analyt. Chem. 47 (2013) 1-11.

[29] M. Abert Vian, X. Fernandez, F. Visinoni, F. Chemat, Microwave hydrodiffusion and gravity, a new technique for extraction of essential oils, J. Chromatogr. A 1190 (2008) 14-17.

[30] A. Farhat, A.S. Fabiano-Tixier, F. Visinoni, M. Romdhane, F. Chemat, A surprising method for green extraction of essential oil from dry spices: microwave dry-diffusion and gravity, J. Chromatogr. A 1217 (2010) 7345-7350.

[31] N. Bousbia, M. AbertVian, M.A. Ferhat, B.Y. Meklati, F. Chemat, A new process for extraction of essential oil from Citrus peels: microwave hydrodiffusion and gravity, J. Food Eng. 90 (2009) 409-413.

[32] N. Bousbia, M. AbertVian, M.A. Ferhat, E. Peticolas, B.Y. Meklati, F. Chemat, Comparison of two isolation methods for essential oil from rosemary leaves: hydrodistillation and microwave hydrodiffusion and gravity, Food Chem. 14 (2009) 355-362.

[33] Zill-e-Huma, M. Abert-Vian, J.F. Maingonnat, F. Chemat, Clean recovery of antioxidant flavonoids from onions: optimising solvent free microwave extraction method, J. Chromatogr. A 1216 (2009) 7700-7707.

[34] Zill-e-Huma, M. Abert-Vian, A.S. Fabiano-Tixier, M. Elmaataoui, O. Dangles, F. Chemat, A remarkable influence of microwave extraction: enhancement of antioxidant activity of extracted onion varieties, Food Chem. 127 (2011) 1472-1480.

[35] S. Périno-Issartier, Zill-e-Huma, M. Abert-Vian, F. Chemat, Solvent free microwave-assisted extraction of antioxidants from sea buckthorn (Hippophae rhamnoides) food by-products, Food Bioprocess Technol. 4 (2010) 1020-1028.

[36] E. Vorobiev, N. Lebovka, Electrotechnologies for Extraction from Food Plants and Biomaterials, Springer, NewYork, 2008.

[37] U. Zimmermann, R. Benz, Electric field-mediated fusion and related electrical phenomena, Biochim. Biophys. Acta 694 (1982) 227-277.

[38] M. Corrales, S. Toepfl, P. Butz, D. Knorr, B. Tauscher, Extraction of anthocyanins from grape by-products assisted by ultrasonics, high hydrostatic pressure or pulsed electric fields: a comparison, Innovative Food Sci. Emerg. Technol. 9 (2008) 85-91.

[39] T. Gachovsk, D. Cassada, J. Subbiah, M. Hanna, H. Thippareddi, D. Snow, enhanced anthocyanin extraction from red cabbage using pulsed electric field processing, J. Food Sci. 75 (2010) 323-329.

[40] E. Puertolas, O. Cregenzan, E. Luengo, I. Alvarez, J. Raso, Pulsed-electric-fieldassisted extraction of anthocyanins from purple-fleshed potato, Food Chem. 136 (2013) 1330-1336.

[41] N. Boussetta, E. Vorobiev, L.H. Le, A. Cordin-Falcimaigne, J.-L. Lanoisellé, Application of electrical treatments in alcoholic solvent for polyphenols extraction from grape seeds, LWT - Food Sci. Technol. 46 (2012) 127-134.

[42] N. López, E. Puértolas, S. Condón, J. Raso, I. Álvarez, Potential applications of PEF to improve red wine quality, LWT - Food Sci. Technol. 42 (2009) 1674-1680.

[43] K.V. Loginova, N.I. Lebovka, E. Vorobiev, Pulsed electric field assisted aqueous extraction of colorants from red beet, J. Food Eng. 106 (2011) 127-133. 